\title{
End-of-life decisions in The Netherlands
}

All over the world medical decisions concerning the end of life are increasingly being discussed between patients, physicians, politicians, ethicists and lawyers. They not only involve euthanasia and assisted suicide but also, for example, forgoing therapy, 'do not resuscitate' orders and pain treatment. This Editorial will, however, mainly concentrate on euthanasia and assisted suicide. The content is based on an objective evaluation of the existing literature and daily practice. It does not necessarily express the author's own opinion on end-of-life decisions in general and particularly on euthanasia and assisted suicide.

In all countries considerable differences exist in opinions between lay people and physicians. Many patients request euthanasia, assistance in suicide, or termination of their treatment because they fear the physical symptoms of terminal illness, the loss of dignity and the suffering of pain. Some patients are afraid to lose the good relationships with their relatives or to become dependent on them. Such considerations lead them to plead for an early death. Grief, depression, anxiety, organic mental disorders and personality disorders are common psychological conditions that may induce the wish to hasten death. Physicians are reluctant to become involved because they frequently struggle with questions of moral, ethical or fundamental medical origin. Sometimes the opinions on both sides are driven by questions with a religious or cultural-historical background.

Most physicians are trained with the fundamental ethical intention to save and prolong life rather than to destroy and shorten it, and with their Hippocratic oath to do good (beneficence) rather than to harm (nonmaleficence). Ethicists are equivocal about forgoing and withdrawing therapy, but still struggle with the potential misuse of euthanasia and assisted suicide in other areas than the terminally ill patient. Legal scientists mainly are worried about justified

Correspondence to: Leo H. D. J. Booij, Department of Anaesthesiology, University Medical Centre Nijmegen, P.O. Box 9101, 6400HB, Nijmegen, The Netherlands. E-mail: 1.booij@anes.azn.nl; Fax: +31 243540524

Accepted for publication January 2002 EJA 891 application and the controllability of the methods used in end-of-life decisions. These opposing feelings result in endless debates with slow political decisions in parliaments. Nevertheless throughout the world the medical community and its patients no longer accept pain and suffering and thus requests to hasten death are increasing everywhere [1].

It cannot be denied that end-of-life decisions, including both euthanasia and physician-assisted suicide, are being undertaken in almost every country of the world, although such practice is officially denied. From the publications which continue to appear it must be concluded that there is a gradual growing acceptance of euthanasia and physicianassisted suicide. However, translation of daily practice into legislation is considerably different and only in a few countries (The Netherlands, Oregon in the USA, and the Northern Territories in Australia) are euthanasia and assisted suicide officially allowed when performed within strict regulations.

In all aspects of euthanasia, physician-assisted suicide, forgoing therapy and withdrawing therapy, autonomy of the patient plays a central role. Probably the fact that patients take the drugs themselves underlies much of the justification for assisted suicide being legally accepted in a number of countries. More physicians apparently accept assisted suicide than they do euthanasia. The ethical difference between the two is small but the difference in feeling for the physician and legislators seems to be extremely large. When talking about euthanasia some physicians approve so-called passive euthanasia but reject so-called active euthanasia. Others disapprove of both. However, passive euthanasia is not euthanasia but either respecting the patient's legal wish not to provide further treatment or to ethically withhold futile treatment allowing the patient to die.

'Do not resuscitate' orders and stopping or withholding other therapy (including resuscitation) nowadays is generally accepted. Both are involved in futile care, which is the continuation of medical treatment that from a medical perspective is not beneficial to the patient. However, many physicians are still unwilling to withdraw lung ventilators from 
patients, or to stop other life-sustaining treatment $[2,3]$. This may even be the case if the patient is dying [4]. Many have a lesser problem by not starting artificial ventilation in the first place $[5,6]$. The reason is often that a decision to withhold treatment is principally the patient's own decision whereas the decision to stop is frequently a decision of the physician and/or a surrogate. The Society of Critical Care Medicine endorsed a consensus report on the ethics of forgoing life-sustaining treatments in which it was concluded that:

'The patient or the patient's surrogate is the source of authorization for decisions to treat or not to treat...'.

\section{Furthermore:}

'... any treatment derives its medical justification from the benefits that the informed patient and the physician bope to achieve employing it. When the treatment has achieved those benefits, or can no longer reasonably be expected to do so, the treatment loses its justification and may be withdrawn...'.

Also:

'A bealthcare professional has no obligation to offer, begin, or maintain a treatment which, in his or her honest judgement, will be physiologically futile...' [7].

These statements are supported by many other medical professional organizations. The American Thoracic Society stated:

'...it is ethically permissible to provide sufficient medication to relieve a patient's pain and suffering arising from withbolding or withdrawing life-sustaining therapy, even if the patient's death may be unintentionally bastened in the process...' [8].

The ethical distinction between withdrawing therapy and the injection of potentially lethal drugs is small. Many ethicists agree that they are equivalent. It is therefore hypocritical to consider the one as unethical and to accept the other. Preventing suffering and ensuring comfort are important duties of physicians and both actions may sometimes be demanded.

More discussion exists around euthanasia, especially the way it is practised in The Netherlands. I will restrict myself to this topic here. Many Dutch physicians consider euthanasia and assisted suicide as part of due care to limit the suffering of the patient or as a method to decrease the duration of dying. This opinion is not limited to The Netherlands but exists in many countries [6,8-10]. Society has now accepted the right of the hopelessly ill individual to decline life-sustaining therapy $[11,12]$. Why therefore should society not accept voluntary euthanasia? Also in The Netherlands most physicians have ambivalent feelings on the subject of euthanasia. Some physicians see a request for euthanasia as proof of the shortcoming in their personal professional ability. The psychological burden that is put on many physicians by a patient's request to hasten death is usually enormous. It may arouse feelings of guilt and fear, not only for the performance of the deed itself but also if the deed is denied. The physician's refusal to help may be experienced by the patient as abandonment, a rejection, or an expression of inappropriate paternalistic authority [13]. For legislators and ethicists pain and suffering are not the only backgrounds of the discussion. They find justification in the basic principle of autonomy, giving the individual the right to decide. The patient making the decision must be competent, conscious, informed and independent. None of these are guaranteed present in all patients, which makes misuse of the decisions possible, demanding strict preventive regulations.

After some earlier provisional legislative measures, The Dutch Euthanasia Act (Review procedures of termination of life on request and assisted suicide and amendment to the Penal Code (Wetboek van Strafrecht)) and The Burial and Cremation Act (Wet op de Lijkbezorging) were passed in The Netherlands in 2000. The Netherlands is the first country where a euthanasia act has been passed by parliament. However, there is enormous misunderstanding about these laws. Contrary to what many believe, euthanasia is still a criminal action. The so-called Euthanasia Law actually is a law which changes two other laws: The Penal Code and more specifically, Article 293 of The Burial and Cremation Act.

The changes defined in the Penal Code concern rules of due care under which a physician will not be prosecuted when the life of a terminally ill person is purposely ended on request (euthanasia) or when help in suicide is provided. In the Burial Act (Article 7.2) it is defined that physicians must provide a declaration of death in which the cause of death is stated as either natural or non-natural. Non-natural death (murder, suicide, accident) is automatically considered to be a criminal offence unless the opposite has been proven. The current change includes that euthanasia must be declared but if the rules stated in the guidelines are fulfilled no further investigation will follow. A regional committee, consisting of a legal specialist, a physician and an ethicist (Article 3), will examine the declaration and review the due care of the action within 6 weeks (Article 9) and report to the Attorney General and the Health Inspector if the rules are not fulfilled adequately. In that case the Public Prosecutor is allowed to seek information from the committee in order to prosecute the physician. 
The regional committees submit a joint annual report to the Minister of Health.

The rules of due care are thus very important limitations and are defined in Article 2 Subsection 1 of the Euthanasia Act as follows:

\section{'The physician}

1. bolds the conviction that the request by the patient was voluntary and well considered,

2. holds the conviction that the patient's suffering was lasting and unbearable,

3. has informed the patient about the situation he was in and about his prospects,

4. the patient holds the conviction that there was no other reasonable solution for the situation he was in,

5. the patient has consulted at least one other independent physician who has seen the patient and has given bis written opinion on the requirements of due care as referred to in the first four parts,

6. has terminated a life or assisted in a suicide with due care.'

In Subsection 2 is it described that if mentally incompetent persons have expressed in written form their desire for euthanasia before they became incompetent the physician must regard this expression as valid. Subsections 2 and 3 concern minors below the age of consent. According to the Penal Code euthanasia and assisted suicide still punishable criminal actions in these cases.

The changed text of the criminal law Article 293 reads as follows:

'1. He whom purposely ends the life of another person on explicit request of that person, is punished by imprisonment of a maximum of twelve years or a fine in the fifth category.

2. The fact as stated in the first subsection is not actionable if it is committed by a physician who fulfilled the rules of carefulness as described in Article 2, Law of testing life termination on request and aid in self ending of life, and whom has notified the coroner according to article 7 subsection 2 of the Burial Law.'

Article 294 contains the same information with respect to assisted suicide.

Many believe that euthanasia has now become routine practice in The Netherlands. However, this is not the case at all. The statistics reveal that in our country $40 \%$ of people die at home, $16 \%$ in nursing homes and $44 \%$ in other health care institutions including hospitals. During the second half of the last decade in The Netherlands end-of-life decisions were taken in $44.2 \%$ of the cases where patients were dying. Euthanasia or assisted suicide was performed in $3.6 \%$ of the deaths, lethal drugs without request in $0.7 \%$, large amounts of analgesics in $19.1 \%$ and withholding therapy in $20.8 \%$ [14]. In comparison, in Belgium end-of-life decisions were involved in $39.4 \%$ of cases [15], in France $58.8 \%$ of cases [16] and in Australia 64.8\% [17]. Thus the situation in The Netherlands concerning end-of-life decisions is not much different from that in many other countries, except that euthanasia and assisted suicide have an incidence which is almost double that elsewhere. However, administration of potentially lethal doses of pain relieving drugs and withholding therapy is lower than in other countries.

It has been proven that assisted suicide is accompanied by more complications (pain and discomfort during execution and failure) than euthanasia. This is the reason why about $10 \%$ of the cases end up as euthanasia (the physician administers the drug). This for a major part is due to the fact that the patients are in such a poor condition that they are not able to administer the drug adequately themselves due to, for example, swallowing problems or they vomited and lost a major part of the medication. A study concerning the problems in physician-assisted suicide has been performed in The Netherlands where a failure rate of 21 out of 114 cases was found [18]. Others have found incidences of failures of $12 \%$ and $7 \%$. For this reason a physician should be present at both euthanasia and assisted suicide.

Because of the many discussions surrounding euthanasia and assisted suicide, a study on the incidence of euthanasia was performed in 1990 and repeated in 1995 (Table 1). Physicians answered that they performed respectively 2700 and 3600 cases. This was about double the incidence officially reported on death certificates. Other studies have revealed that in 1990, deaths in 2000 ( $1.7 \%$ of cases) were by euthanasia; assisted suicide took place in $200(0.2 \%)$. In 1995 the figures were respectively $2.4 \%$ and $0.2 \%$.

In 1991 a national investigation into the incidence of euthanasia and assisted suicide was performed and the results of this study were published internationally. Not only were 405 physicians (152 general

Table 1. Studies on deaths and the incidence of euthanasia in The Netherlands, 1990 and 1995.

\begin{tabular}{lcc}
\hline & 1990 & 1995 \\
\hline Deaths (total) & 128786 & 135546 \\
Euthanasia & $1.7 \%$ & $2.4 \%$ \\
Assisted suicide & $0.2 \%$ & $0.2 \%$ \\
Life termination without request & $0.8 \%$ & $0.7 \%$ \\
High dose opioids & $18.8 \%$ & $19.1 \%$ \\
Withdrawing care & $17.9 \%$ & $20.8 \%$ \\
Total interference & $39.4 \%$ & $42.6 \%$ \\
\hline
\end{tabular}


Table 2. Investigation into the incidence of euthanasia and assisted suicide in The Netherlands, 1991.

\begin{tabular}{lcccl}
\hline & $\begin{array}{l}\text { Part 1 } \\
(\%)\end{array}$ & $\begin{array}{l}\text { Part 2 } \\
(\%)\end{array}$ & $\begin{array}{l}\text { Part 3 } \\
(\%)\end{array}$ & $\begin{array}{l}\text { Best estimate } \\
(\%)\end{array}$ \\
\hline Euthanasialsuicide & - & 2.7 & 4.7 & 2.9 \\
Euthanasia & 1.9 & 1.7 & 2.6 & 1.8 \\
Suicide & 0.3 & 0.2 & 0.4 & 0.3 \\
Without request & - & 0.8 & 1.6 & 0.8 \\
Pain treatment & 16.3 & 18.8 & 13.8 & 17.5 \\
No treatment & - & 17.9 & 17.0 & 17.5 \\
Total & - & 39.4 & 35.4 & 38 \\
\hline
\end{tabular}

physicians, 50 nursing home physicians, 203 medical specialists) interviewed (Part 1), but also death certificates were analysed for the cause of death (Part 2). It was prospectively agreed that the interviewed physicians would report on their actions to patients that died (2257) in their practices during 6 months after the interview (Part 3) [19]. It was concluded that over 25000 requests for hastening death were expressed by patients annually; in 9000 cases it came to explicit requests of which about one-third were accepted and resulted in interference with the process of dying. Almost all requests concerned terminally ill patients (1 week life expectancy in 58\% and $<1$ month in $83 \%$ ). The results of these studies gave the incidences of actual actions (Table 2).

Of all Dutch physicians 50\% had been involved in euthanasia, $29 \%$ during the last year; $35 \%$ of physicians are not willing to administer euthanasia at all. Furthermore, the study concluded that in more than one-third of the annual deaths in The Netherlands there was some interference by a physician (49000 in 130000$)$. Such interferences were: (a) withholding further treatment, (b) discontinuation of life support, (c) alleviation of pain and symptoms with drugs that might hasten death.

Other studies which have been performed indicated that not all requests ended in actual euthanasia or assisted suicide. In 1990 there were 8900 requests, 2300 cases of euthanasia, 242 assisted suicides and 976 endings of life without request. In 1995 this was 9700 requests, 3600 cases of euthanasia, 238 assisted suicides and 1466 endings of life without request. It was also demonstrated that in the discussion about end-of-life decisions the religion of the patient is taken into consideration by the physician [20].

Considerable information exists as to why patients demand euthanasia. The factors involved are: $57 \%$ loss of dignity, $46 \%$ experience or fear of pain, $33 \%$ fear of dependency, and $23 \%$ tiredness of life [19]. Another study found similar figures: $29 \%$ futile suffering, $24 \%$ avoidance of humiliation, $18 \%$ unbearable suffering, and $40 \%$ fear of pain [21]. These are not different from the figures found in other countries.
It is frequently stated in other countries that euthanasia will affect the relationship between physician and patients. Patients do not trust their physicians any longer because of the fear of having their life ended prematurely. In practice this seems not be the case. So far all court cases regarding unwanted suicide have involved nurses and never physicians. Dutch physicians are very reluctant to aid in euthanasia and spend a long time in consideration before they assist in the act. In addition, if the proper definition of euthanasia is used, the will of the patient is the main determinant and thus fear of misuse should not exist. Contrary legalization will allow the physician to also legally provide optimal care to the individual. Euthanasia than can become an additional treatment and does not disrupt the relationship.

Autonomy and beneficence are important principles in The Netherlands. This might be the reason why many citizens make up their own minds - this is reflected in the high percentage of elderly and terminally ill patients who possess advanced treatment directives. In palliative care departments or institutions such advance directives are present in The Netherlands in $92 \%$, in the USA in $79 \%$, in Germany in $18 \%$ and in Japan in $9 \%$ of patients [22]. Contrary to many other countries an economic reason for euthanasia does not exist in The Netherlands. Almost $100 \%$ of the population in The Netherlands have medical insurance, especially for protracted illness, and the social system is such that financial inability is no reason for stopping treatment or ending life. Hospitals and physicians by law have no financial incentives to stop medical treatment. Hospitals, for example, are not legally allowed to make financial profits.

At this very moment many discussions are ongoing because physicians refuse to aid in suicide where patients demand it. Some seem to believe that they have a right to choose euthanasia just as they do to select palliative care. All these decisions evoke ethical discussions.

\author{
Leo H. D. J. Booij \\ Department of Anaesthesiology \\ University Medical Centre Nijmegen \\ Nijmegen, The Netherlands
}

\section{References}

1. Block SD, Billings JA. Patient requests to hasten death. Evaluation and management in terminal care. Arch Intern Med 1994; 154: 2039-2047.

2. Faber-Langendoen K, Bartels DM. Process of forgoing lifesustaining treatment in a university hospital: an empirical study. Crit Care Med 1992; 20: 570-577. 
3. Smedira NG, Evans BH, Grais LS, et al. Withholding and withdrawal of life support from the critically ill. $N$ Engl $J$ Med 1990; 322: 309-315.

4. Faber-Langendoen $\mathrm{K}$. The clinical management of dying patients receiving mechanical ventilation. A survey of physician practice. Chest 1994; 106: 880-888.

5. Caralis PV, Hammond JS. Attitudes of medical students, housestaff, and faculty physicians toward euthanasia and termination of life-sustaining treatment. Crit Care Med 1992; 20: 683-690.

6. Fried TR, Stein MD, O'Sullivan PS, Brock DW, Novack DH. Limits of patient autonomy: physician attitudes and practices regarding life-sustaining treatments and euthanasia. Arch Int Med 1993; 153: 722-728.

7. Consensus report on the ethics of foregoing life-sustaining treatments in the critically ill. Crit Care Med 1990; 18: 1435-1439.

8. American Thoracic Society. Withholding and withdrawing life-sustaining therapy. Ann Int Med 1991; 115: 478-485.

9. Brock DW. Voluntary active euthanasia. Hastings Cent Rep 1992; 22: 10-22.

10. Brody H. Assisted death - a compassionate response to a medical failure. N Engl J Med 1992; 327: 1384-1388.

11. Orentlicher D. Physician participation in assisted suicide. JAMA 1989; 262: 1844-1845.

12. Rosenblum VG, Forsythe CD. The right to assisted suicide: protection of autonomy or an open door to social killing? Issue Law Med 1990; 6: 3-31.

13. Cassel CK, Meier DE. Morals and moralism in the debate over euthanasia and assisted suicide. N Engl J Med 1990; 323: 750-752.
14. van der Maas PJ, van der Wal G, Haverkate I, et al. Euthanasia, physician assisted suicide, and other medical practices involving the end of life in The Netherlands, 1990-1995. N Engl J Med 1996; 335: 1699-1705.

15. Deliens L, Mortier F, Bilsen J, et al. End-of-life decisions in medical practice in Flanders, Belgium: a nationwide survey. Lancet 2000; 356: 1806-1811.

16. Noel K, Hinglais E, Devictor D. Opinions de medecins generalistes face aux fins de vie à domicile. Press Med 1999; 28: 692-694.

17. Kuhse H, Singer P, Baume P, Clark M, Rickard M. Endof-life decisions in Australian medical practice. Med J Aust 1997; 166: 191-196.

18. Groenewoud JH, van der Heide A, Onwuteaka-Philipsen B, Willems DL, van der Maas PJ, van der Wal G. Clinical problems with the performance of euthanasia and physicianassisted suicide in the Netherlands. N Engl J Med 2000; 342: 551-556.

19. Van der Maas PJ, van Delden JJ, Pijnenborg L, Looman CW. Euthanasia and other medical decisions concerning the end of life. Lancet 1991; 338: 669-674.

20. Kuyck WG, de Wit NJ, Kuyvenhoven MM. Do doctors pay attention to the religious beliefs of their patients? A survey amongst Dutch GPs. Fam Pract 2000; 17: 230-232.

21. Van der Wal G, van Eijk JT, Leenen HJ, Spreeuwenberg C. Euthanasia and assisted suicide II: Do Dutch family doctors act prudently? Fam Pract 1992; 9: 135-140.

22. Voltz R, Akabayashi A, Reese C, Ohi G, Sass HM. End-oflife decisions and advance directives in palliative care: a cross cultural survey of patients and health-care professionals. J Pain Symptom Manage 1998; 16: 153-162. 